\title{
Thermonuclear fusion
}

\section{US community asks for next machine}

\section{Washington}

FUSION researchers in the United States are making a strong pitch for a new tokamak machine that will reach plasma ignition the point at which fusion becomes selfsustaining without additional external heating. To maintain the "three-year lead" gained by the start-up of the Tokamak Fusion Test Reactor (TFTR) at Princeton, Dr Harold Furth, director of the Plasma Fusion Laboratory there, told a congressional committee last week that the United States should start serious planning now for the new machine so that construction could begin in 1987 . Furth said that the new machine, dubbed the Tokamak Fusion Core Experiment (FTCX), could be operational by 1992 .

The existing TFTR is expected to reach scientific break-even, the point where the fusion reaction is generating as much power as is being applied to heat and confine the plasma. The new TFCX would boost confinement (the product of density and confinement time) by roughly an order of magnitude over that which TFTR will achieve pushing the plasma to ignition with confinement times of as long as 5 minutes. The cost of TFCX, for which no detailed

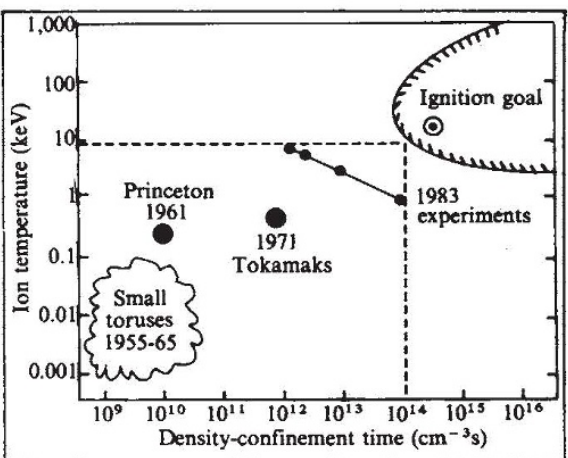

Break-even conditions for thermonuclear fusion based on the "Lawson criterion". The diagonal line labelled 1983 experiments shows the results of various machines reaching the ignition conditions independently (although not all at the same time).

design has yet been produced, is estimated at less than $\$ 1,000$ million.

Furth said that recent results have given the fusion research community new confidence that ignition can be achieved. Separate experiments around the country have independently demonstrated the conditions necessary for ignition; ion temperatures of the order of 100 million degrees, confinement times of the order of a second, and density-confinement - time factors of $10^{14} \mathrm{~cm}^{-3} \mathrm{sec}$.

The Department of Engery's magnetic fusion budget has suffered from fairly tight constraints in recent years, growing at no more than the inflation rate, and there seems little likelihood of much change. The budget is now $\$ 471$ million; $\$ 483$ million has been requested for fiscal year 1985 .

Although TFCX has received broad support from the fusion research community - both the Engergy Research Advisory Board and the Magnetic Fusion Advisory Committee (MFAC) have called it the number one priority in fusion research - a go-ahead for the project may cause some strains. Several witnesses at last week's hearing expressed concern about what would happen to the base of fusion research at the universities if TFCX were to be built within the present budget. Ronald Davidson, director of the Massachusetts Institute of Technology's Plasma Fusion Center and chairman of MFAC, asked for a gradual "ramp-up" by $20-40$ per cent to allow TFCX to begin without harming the existing programme. The Department of Energy is expected to allocate $\$ 10-20$ million in fiscal year 1985 for conceptual design studies, although the budget contains no specific request for the project. The first indication of how the fusion research budget will be treated in the light of TFCX will come next year, when money for actual design work may be requested.

Congress is seen as generally supportive of the fusion effort - particularly because of the threat of foreign competition. Dr Allan Mense of McDonald Douglas Company, representing the Institute of Electrical and Electronics Engineers, ritually invoked the Japanese and Soviet menaces at last week's hearings, noting that while the US fusion budget has grown by less than 5 per cent per annum since 1977, Japan's programme has been growing at 30 per cent per annum. The closest competitors to TFTR are the Joint European Torus in the United Kingdom and two machines expected to begin operating in late 1985 or early 1986 , Japan's JT-60 and the Soviet Union's $\mathrm{T}-15$.

\section{US electronics \\ Fifth generation stillborn?}

\section{Los Angeles}

A CONSORTIUM of US electronics companies created to build the "next generation" of computers before the Japanese is having difficulty attracting first-rate scientists to join the effort.

"Assembling the talent and getting the research under way has not been going as fast as I would like" says Bobby Inman, president of the Micro-electronics and Computer Technology Corporation (MCC), now setting up shop in Austin, Texas.

Mr Inman, former US Navy admiral, director of the National Security Agency and deputy director of the Central Intelligence Agency, said he recently offered key managerial jobs to four people who turned him down.

A quarter of the electrical engineering and computer science faculty at the University of California at Berkeley has been approached by MCC and none has shown interest. Leading scientists at the Massachusetts Institute of Technology and Carnegie Mellon University, who attract talented subordinates, have also refused offers.

MCC was created last year to pool the resources of 14 high-technology companies for a crash programme to develop advanced "fifth generation" computers using so-called expert systems and artificial intelligence programs. Copying a similar Japanese effort, MCC will share scientific breakthroughs, if any, with its member companies. Details of how that is to be done have still not been worked out and the consortium remains controversial.
MCC is an unproven enterprise, according to scientists who have refused $\mathrm{Mr}$ Inman's offers. There is a shortage of people able to design and program advanced computers and the best of them are content with their present jobs. MCC is trying to establish a "quality research team" in a hurry but, the scientists say, such a thing cannot be rushed.

Some academics said they do not feel an ex-military officer can create the "optimum environment for research", although $\mathrm{Mr}$ Inman's Washington connections are invaluable for MCC.

Several states sought to have MCC established on their turf, expecting to accrue prestige and scientific talent. But states that lost seem to be faring better than Texas, which won. Stung by criticism that he bungled efforts to land MCC, the governor of California this year substantially raised faculty salaries. Georgia, MCC's second choice, used publicity gained from the competition to lure new high-technology companies to Atlanta. North Carolina did likewise. The governor of Texas, meanwhile, is saddled with a promise to bring MCC $\$ 23.5$ million in private donations. This is on top of $\$ 40$ million from state coffers, which have been depleted by falling oil revenues.

Mr Inman is not perturbed. "It's awfully early for a report card", he says. "I'm a good five months ahead of my worst case and about four months behind my fastest track." Of an expected 300 employees, "We have 64 people here as of today. The cast of characters continues to surge."

Sandra Blakeslee 